\title{
GRAVEL BEACH PROFILE EVOLUTION IN WAVE AND TIDAL ENVIRONMENTS
}

\begin{abstract}
Mohamad H. Jamal ${ }^{1,2}$, David J. Simmonds ${ }^{1}$, Vanesa Magar ${ }^{1}$
This paper reports progress made in modifying and applying the X-Beach code to predict and explain the observed behaviour of coarse grained beaches. In a previous study a comparison of beach profile evolution measured during large scale experiments under constant water level with numerical model simulations was made. This placed particular emphasis on the tendency for onshore transport and profile steepening during calm conditions (Jamal et al., 2010). The present paper extends that investigation to study the influence of the advection of surf processes induced by tidal water level variations effects, on gravel beach profile evolution. The parameter values and numerical model used in the simulation is similar to that presented previously. It is assumed that, to good approximation, the groundwater interface inside the beach follows the tidally modulated water level. The results obtained from the model shows that the model provides reasonable simulations of beach profile change in a tidal environment. In comparison with simulations under stationary water levels, a larger berm is produced in agreement with literature. Finally, good agreement is obtained between the model simulations and an example of field observations from a beach at Milford on Sea, UK. Further developments are outlined for future work.
\end{abstract}

Keywords: gravel beach; tides; infiltration; sediment transport; numerical modelling

\section{INTRODUCTION}

Interest in coarse grained, gravel and shingle beach environments and particularly in the predicting of their dynamic behaviour in response to wave climate and water level variation has been increasing in recent years (Bradbury, 2000, Williams et al., 2012). In the UK Gravel and shingle beaches form important natural coastal defence protecting substantial urban areas such as Southampton, which shelters behind Hurst spit, and designated habitats of scientific and interest and recreational value such as Chesil Beach. These beaches are also associated with protection of items of key infrastructure such as Hinckley Point power station where understanding their response to extreme events affects more than calculations of flood risk. They occur naturally at the bases of some cliff systems, where they enhance toe protection, such as at Hordle Cliff. Furthermore, soft engineering approaches involving the replenishment of an eroding beach will often advocate the use of coarse material or mixed sand and gravel (Mason et al. 2007).

Therefore, the development of tools for understanding the adaptive behaviour of coarse-grained beaches in response to short-term and long-term forcing is vital for coastal management and flood defence planning. The waves, tides and sea level changes that represent the system forcings provoke different responses on coarse sediment beaches in comparison to sand beaches, dictated by the sediment size and consequent porosity. Indeed, Masselink and Short's (1993) conceptual model of beach types captures most generic classes of profile uses only two parameters: relative tidal range and sediment fall velocity which are both normalised by significant wave height.

Until recently, the most practical, and successful approach to describing coarse beach profiles was provided by the Powell parametric model (Powell, 1990). This model, based upon defined water levels and a series of intersecting curves was generally acknowledged to provide a very workable description of observed coarse grained beach profiles. In this work we examine the adaptation and use of a public domain numerical model, X-beach (Roelvink et al., 2009 and van Thiel de Vries, 2009), based upon the non-linear shallow water equations, for capturing the 2-D profile dynamics of a gravel beach, through consideration of wave and tidal forcing, building on the work of Jamal et al. (2010).

\section{BACKGROUND OF GRAVEL BEACH PROCESS AND MORPHOLOGY}

In order to predict the dynamic behaviour of gravel beaches, it is necessary to consider the complex balance of processes that controls the dynamics of the sediment. Physical processes in the swash have are known to control erosion and accretion at the shoreline (Puleo et al. 2000). This is especially true of steeper, coarse grained beaches where the surf zone is much narrower and closer to the shoreline than on sandy beaches. Swash motions, here, are shaped by inner surf zone processes mechanisms and the topography of the beach face (Pedrozo-Acuña, 2005) and in particular the form of wave breaking. Plunging is the dominant mode of breaking on steeper beaches. Under plunging breakers, the velocity on the wave crest is much higher than the wave trough. Breaking creates energetic bores which

\footnotetext{
${ }^{1}$ Coastal Engineering Research Group, University of Plymouth, Drake Circus, PL4 8AA, Plymouth, United Kingdom

${ }^{2}$ Faculty of Civil Engineering, Universiti Teknologi Malaysia, 81310 Johor Bahru, Johor, Malaysia
} 
collapse very near to the shoreline and which subsequently travel up the beach driving the swash oscillations (Baldock and Holmes, 1997). Thus a shoreward asymmetry in the velocity profile exists which pushes turbulent flow shoreward (Ting and Kirby, 1994) into the swash, where dissipation takes place over a short distance. The turbulence that persists into the swash has been observed to exhibits greater intensity in the up-rush than the backwash (Hughes et al. 1997).

The effects of such asymmetry in the cross shore velocity upon the resulting sediment transport in the swash zone is further enhanced by infiltration of a proportion of the run-up which sinks into the porous surface to be ex-filtrated lower down the beach face. Packwood (1983) observed that the effect of infiltration is more significant on uprush than backwash. This increases the sediment transport rate particularly during up-rush (Turner and Masselink 1998) so that the asymmetry in the flow creates an asymmetry in the cross-shore flux of sediment transport. Indeed many studies have stressed the importance of infiltration to sediment transport in the swash region and especially on coarse beaches (e.g. Austin and Masselink 2006, Pedrozo-Acuña et al. 2006, 2007).

The material property that most controls the degree of infiltration is the permeability or hydraulic conductivity of the beach material (Masselink and Li 2001). The average value of permeability of sand is about $0.0001 \mathrm{~m} / \mathrm{s}$ and may rise to $0.01 \mathrm{~m} / \mathrm{s}$ on coarse sand while permeability on gravel varies from $0.001 \mathrm{~m} / \mathrm{s}$ to $0.1 \mathrm{~m} / \mathrm{s}$ (Foote et al., 2002). This creates a significant difference in the magnitude of asymmetry in sediment transport efficiencies between gravel and sand beaches. It has also been proposed that infiltration can be viewed as altering the bed shear stress (Puleo and Holland, 2001) creating greater stress during the up-rush, whilst in the backwash ex-filtration lowers the stress (Conley and Inman, 1994, Nielsen et al. 2001). This manifests as enhanced pickup and greater bed load transport in the up-rush. However Pedrozo-Acuña et al. (2007) found that variation of this friction factor by itself was not able to reproduce the berm features measured on gravel and mixed beaches. On the other hand, their use of separate friction factors in each phase of the swash improves prediction of the beach profiles. The degree of soil saturation on the beach and existence of encapsulated air in the soil might also alter the rate of infiltration.

The propensity for onshore transport in the swash is counteracted by the down-slope weight of the sediment, which eventually brings an accreting beach face to a dynamic equilibrium with the incident wave conditions. This balance thus occurs for steeper gradients on coarse, permeable beaches than on sandy, beaches where the permeability is typically much lower.

The effect of tides on beach morphology has been studied for many years (e.g. Masselink and Hegge, 1995). The sediment transport rate varies throughout the tidal cycle being greater during flood and lesser during ebb (Horn and Mason, 1994). Therefore, the berm might remain on the upper beach. According to Powell (1990) tides will not affect the shape and slope of the gravel beach profile but it may determine the location of the profile on the beach face. However, Trim et al. (2002) found that under constant water level, the beach change is just around the mean water level while with tide the whole beach face will be affected. The tide will also increase the size of the berm and move the berm landward under swell condition and move the bar seaward under storm condition depending on the initial slope and wave climate (Trim et al. 2002).

This raises the issue of how the level of the groundwater within the beach is related to the tide and how this affects infiltration and sediment transport.

The interaction between the surface water flow and groundwater has been widely acknowledged as a key factor in controlling gravel beach morphology (e.g. Mason and Coates 2001), but the exact nature of the relationship between surface flows, groundwater flow and cross-shore sediment transport is still not fully understood. The higher the groundwater level in the backshore, the higher the offshore directed sediment transport as this reduces the infiltration rate (Quick, 1991). Lee et al. (2007) support this view from their laboratory experiment which shows that infiltration on low water table will increase accretion while exfiltration with a high water table promotes erosion. On a coarse beach, up-rushing, as above, will infiltrate rapidly into the beach so long as the run-up is above the level of the water table, depositing sediment on the upper beach (Horn, 2002). In fact, the water table (phreatic) surface inside the beach is not generally not flat, especially on sandy beaches and several authors have shown that it is affected by tidal elevation, sloping seaward on a falling tide and landward on a rising tide (e.g. Raubenheimer et al., 1999). This is illustrated in Figure $1<$ which conceptualises the slope of the phreatic surface at different phases of a tide. Through a series of field measurements at Slapton beach, UK, Austin and Masselink (2006) found that the groundwater level was closely linked to the tidal elevation throughout flood and ebb. Generally, Slapton beach is porous and permeable hence permits water to percolate quickly inside the beach. Greater permeability on gravel beaches is expected to 
provide a quick response between the surface water and ground water compared to sandy beaches, thereby reducing the asymmetry observed in sandy beaches. Thus, within a gravel beach, the groundwater level can be assumed as a continuation of the mean water surface into the beach, and therefore to have the same elevation as the tide (Horn, 2006).

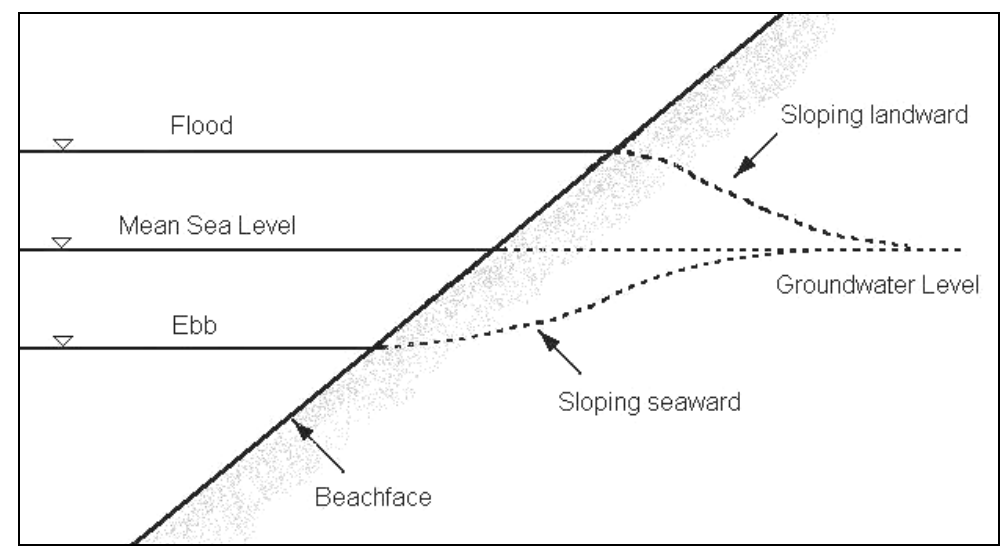

Figure 1: Tide and groundwater level

\section{RECENT PROGRESS IN MODELLING}

Serious attempts have been made to model sediment transport in the swash zone of coarse beaches despite this complexity. For instance, models have been reported by Wurjanto and Kobayashi (1993), van Gent (1994) and others for simulating flow within and above a porous beach. Although these models allow for infiltration/exfiltration and have been validated for surface elevation and flow velocities, they have not been used to investigate the effect of this process on sediment transport and beach profile evolution.

Pedrozo-Acuña et al. (2006) reported an experimental and numerical investigation of cross-shore profile change of gravel beach. A time-dependant morphodynamic model was developed from the Boussinesq model COULWAVE (Lynett et al., 2002) which features an essential moving shoreline boundary for the swash region. This was coupled to a reductivist Meyer-Peter and Müller (1948) sediment transport formulation. They found that the numerical predictions were opposite to observations when the shear stress and transport efficiency are maintained during both the uprush and the backwash phases. This created an incorrect offshore movement of sediment created by the gravity driven asymmetry of the swash velocity. By adjusting the transport efficiency with swash direction, a better prediction of behaviour was obtained. This ad hoc adjustment of parameters was interpreted as an encapsulation of several processes including the infiltration of water into the porous beach-face and accelerated flow post-breaking.

Therefore, it is important to develop a reliable technique as a numerical tool for simulating coarse beach profile evolution in response to wave and currents forcing conditions.

\section{XBeach Variant for Gravel}

In the previous International Conference on Coastal Engineering (ICCE), Jamal et al. (2010) reported on preliminary work which modified the robust and well known public domain modeling system, XBeach for use on porous beaches. They showed how the original model, conceived of for predicting erosion of dunes, could be adapted to simulate gravel beach accretion with a good agreement with large scale laboratory data (Jamal et al., 2010). The present paper extends that investigation to study the influence of the advection of surf processes induced by tidal water level variations effects, on gravel beach profile evolution. Here, the public domain numerical model, XBeach variant modified and improved to be used on coarse beaches by Jamal (2011) is used. Improvements include: use of Lagrangian interpretation of velocity in place of Eulerian for driving sediment movement; introduction of a new morphological module based upon Soulsby's sediment transport equation for waves and currents (Soulsby, 1997); and incorporation of Packwood's (1983) infiltration approach in the unsaturated area of the swash region. These changes were suggested and justified in order to significantly improve the application of this model to gravel, especially with regard to swash velocity asymmetry which is responsible for development of the steep accretionary phase steep berm above waterline. The detail of these improvements can be found in Jamal et al. (2010, 2011). 
A comparison between a previous model simulation and new simulations with tidal excursion is presented with particular regard to the tendency for onshore transport and profile steepening. This is intended to demonstrate the robustness and stability of the X-Beach system for exploring beach dynamics.

\section{SIMULATIONS WITH AND WITHOUT TIDAL EXCURSION}

In this section, the aim is to compare simulations of profile change under stationary and tidal scenarios, using previous reported results for former (Jamal et al, 2011). The scenario used for this purpose of this preliminary analysis was taken from the series of experiments on gravel and mixed beaches undertaken at the Large Wave Channel (GWK) of the Coastal Research Centre (FZK) in Hannover, Germany: "Large scale modelling of coarse grained beaches” detailed in López de San Román-Blanco (2003). The GWK channel is $342 \mathrm{~m}$ long, $7 \mathrm{~m}$ deep and $5 \mathrm{~m}$ wide with a permanent impermeable slope of 1:6 at the beach end. The average beach slope was initially constructed as 1:8. The sediment used was a gravel between 16 and $32 \mathrm{~mm}$ diameter, with actual $\mathrm{D}_{50}=21 \mathrm{~mm}$. The beach porosity was found to vary slightly between 0.42 and 0.46 , average 0.44 . For this particular test regular waves of height $0.6 \mathrm{~m}$ and wave period of $3.22 \mathrm{~s}$ were generated. These values were previously used to compare the measured and simulated profile change with a good agreement found (Jamal, 2011).

In order to model tidal excursion and investigate the model's capability for predicting profile response in tidal (i.e. non stationary water level), the approach was to assume that the water table and the free surface of the external water will be closely coupled by virtue of the relatively high permeability of the sediment. That is, the unsaturated areas on the beach which will always follow the level of the surface water elevation. The new simulation uses a simplistic sinusoidal water level variation with semidiurnal timescale to represent the effect of the tide (Figure 2). The tidal parameters used for this were: tidal range $2.5 \mathrm{~m}$; ebb at $3.2 \mathrm{~m}$; flood at $5.7 \mathrm{~m}$ relative to the datum corresponding to the GWK test (Figure 2). This represents a typical meso-tidal excursion and was chosen to fit within the constraints of the experiment. The preliminary X-Beach simulations presented here also used parameters taken from Jamal et al. (2010): permeability of $0.02 \mathrm{~m} / \mathrm{s}$ and friction factor 0.015 respectively.

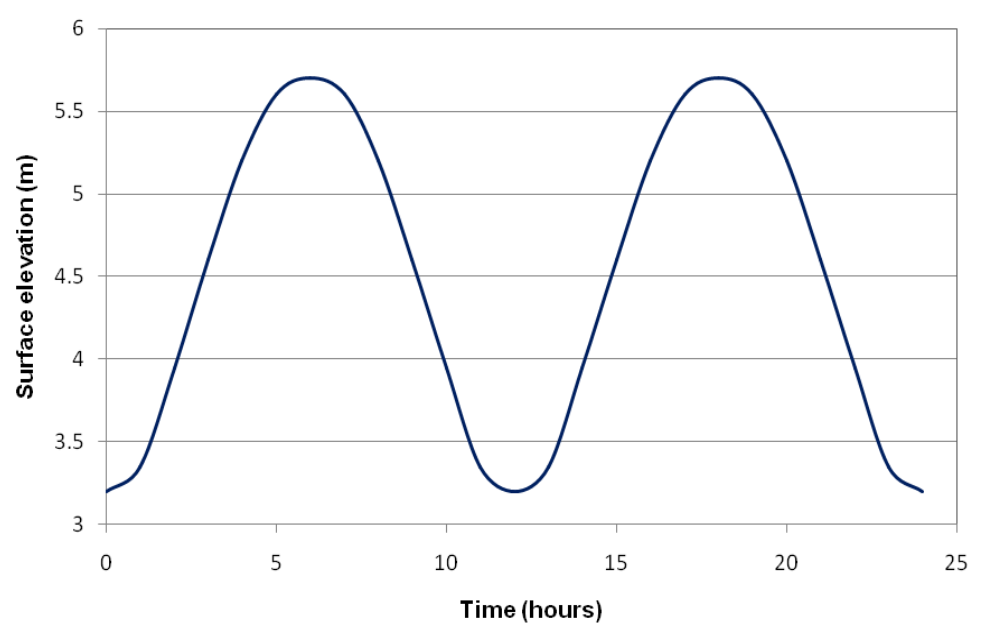

Figure 2: Tidal cycle created for comparison with under constant water level of GWK experiment

Figure 3 and Figure 4 shows results of this simulation. This profile has features in common with the non-tidal accretionary profiles shown in the previous work. Figure 3 shows the first flood and the first ebb of the tidal cycle. Based on that, the sediment is eroded from the lower beach and carried further up the beach as the surface water rises due to flood and the sediment is deposited on the upper beach. On the second flood more sediment is carried into the upper beach and the size of the berm increases (Figure 4). On the second ebb not much change was found, but still the sediment is carried up the slope. This profile agrees with field observations of Horn and Mason (1994) which shows that the sediment transport rate varies throughout the tidal cycle, being greater during flood and lesser during ebb. Therefore, the berm persists on the upper beach. 


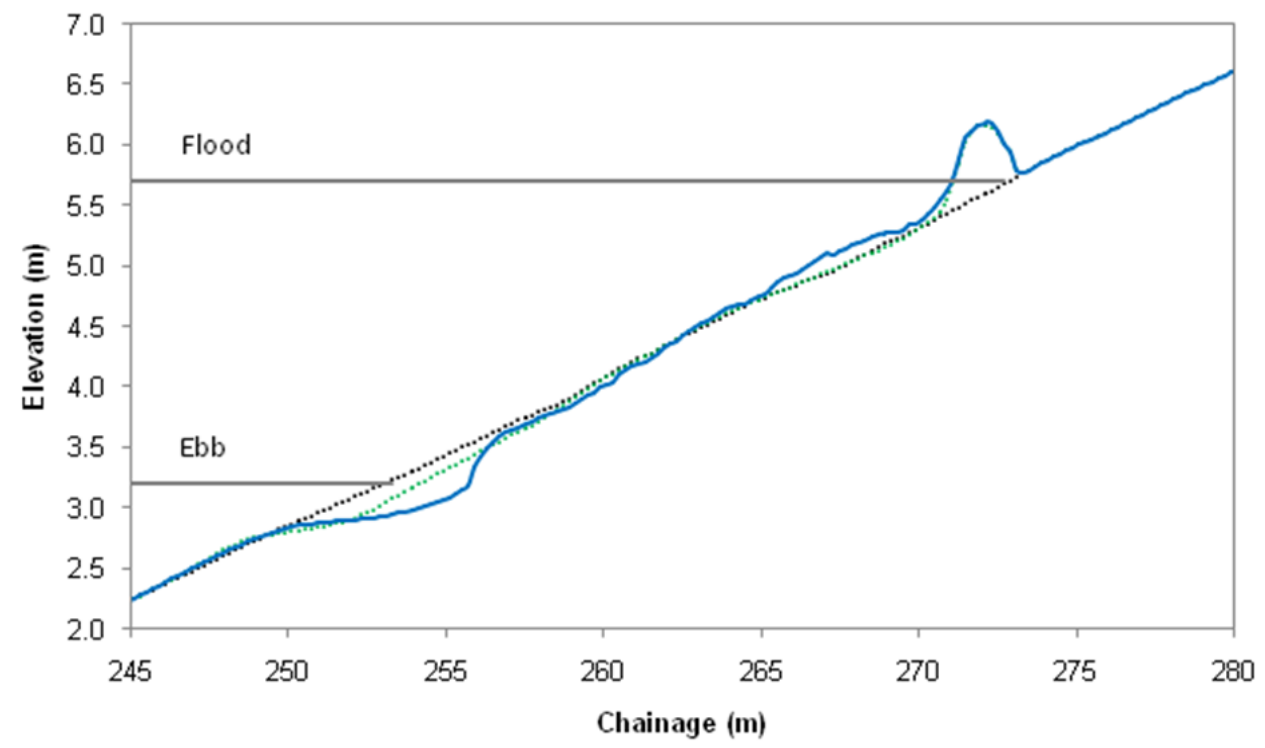

Figure 3: Tide simulation on gravel beach after first tidal cycle $(K=0.02 \mathrm{~m} / \mathrm{s})$ : initial profile - dotted black; profile after $1^{\text {st }}$ flood - dotted green; profile after $1^{\text {st }} \mathrm{ebb}$ - solid blue

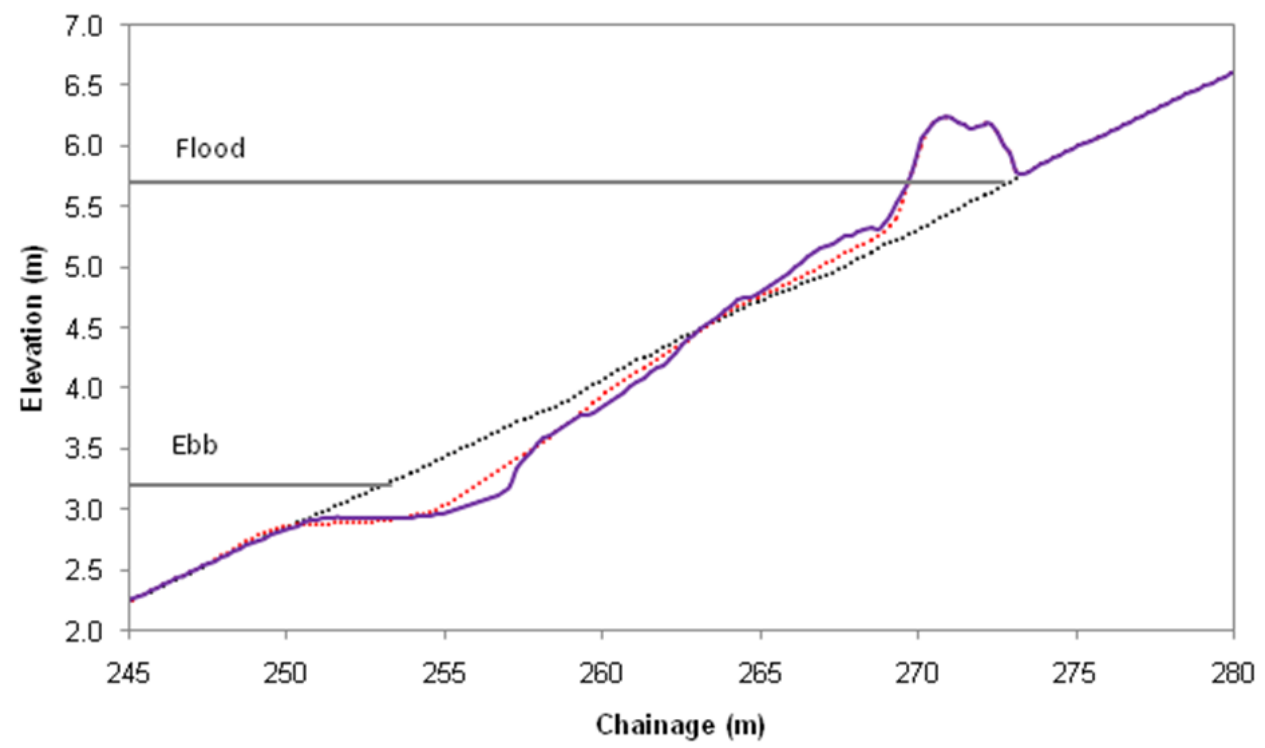

Figure 4: Tide simulation on gravel beach after two tidal cycle $(K=0.02 \mathrm{~m} / \mathrm{s})$ : initial profile - dotted black; profile after $2^{\text {nd }}$ flood - dotted red; profile after $2^{\text {nd }} \mathrm{ebb}$ - solid purple

This preliminary investigation showed that the model was able to predict anticipated features of profile change associated with a gravel beach under such wave and tidal forcing. Figure 5 compares a tidally forced accretion with those predicted under similar beach sediments and wave conditions for constant water level. The figure shows that the affected area of the beach for a day of semidiurnal tide simulation is around $25 \mathrm{~m}$ (chainage $248-273 \mathrm{~m}$ ). As might be expected, the extent of the beach profile change for a stationary mean water level is less, only covering $10 \mathrm{~m}$, between chainage $258 \mathrm{~m}$ and $268 \mathrm{~m}$. This result agrees with the result obtained in the laboratory experiments of Trim et al. (2002) which shows that the affected area is wider with tidal fluctuation than under constant water level. The location of the predicted berm was also consistent reported observation (Powell, 1990): i.e. that the berm appears above the intersection of the high water with the beach face. The berm is also found to be bigger in comparison to the berm with under non-tidal conditions in agreement with Trim et al. (2002). Therefore, the effect of tide can be seen to smear these features over a wider region with bigger berm 
size above the flood line, as anticipated. However this demonstrates the ability of this X-Beach variant to simulate many hours or profile change.

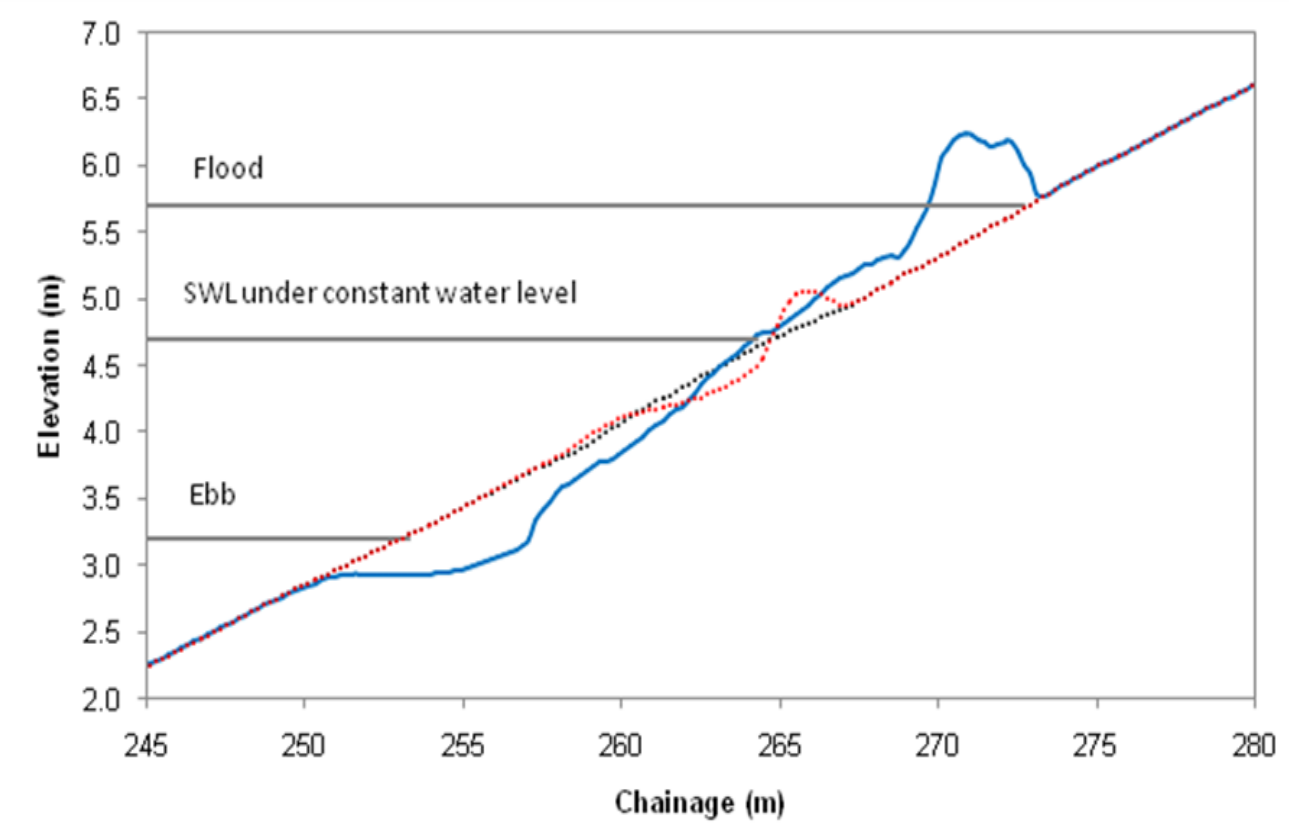

Figure 5: Gravel beach profile simulation results: simulation of 1 day semidiurnal tide (solid blue); simulation of $\mathbf{3 0 0 0}$ waves under constant water level (dotted red); initial beach profile (dotted black)

\section{SIMULATIONS COMPARED WITH FIELD EXPERIMENT}

In order to gain confidence with the new code, further validation has begun, using field data obtained from a field site at Milford, UK. in October 2007. The field site is actually a composite beach with gravel upper beach face and berm, with a lower sandy terrace (Simmonds et al. 1997). The sediment size used in the simulation is based on the measured $D_{50}=7.2 \mathrm{~mm}$. For the purpose of this comparison, the a smaller permeability of $0.005 \mathrm{~m} / \mathrm{s}$ was used. This value was chosen to reflect the lower permeability caused by the presence of finer sediment.

However, subtleties related to sediment mixing, armouring and horizons within the beach are beyond the complexity of the current modelling. Thus, the comparison is not expected to capture the dynamics of the lower sandy terrace at this stage, and focuses on the upper beach and berm. A friction factor of 0.02 was used and transport coefficient of 12 which Soulsby and Damgaard (2005) suggest is suitable for coarse material. The wave data used to drive the simulation was based on the field observations averaged over 2 hours intervals (Table 1). The tidal modulation of the mean water level is derived from field observations (shown in Figure 6) and the simulation represents 22 hours.

\begin{tabular}{|c|c|c|c|c|c|}
\hline \multicolumn{7}{|c|}{ Table 1: Wave data } \\
\hline $\begin{array}{c}\text { Time } \\
(\text { hours })\end{array}$ & $\begin{array}{c}\text { Wave Height } \\
(\mathrm{m})\end{array}$ & $\begin{array}{c}\text { Wave Period } \\
(\mathrm{s})\end{array}$ & $\begin{array}{c}\text { Time } \\
(\text { hours })\end{array}$ & $\begin{array}{c}\text { Wave Height } \\
(\mathrm{m})\end{array}$ & $\begin{array}{c}\text { Wave Period } \\
(\mathrm{s})\end{array}$ \\
\hline $0-2$ & 1.34 & 7.06 & $12-14$ & 0.46 & 8.22 \\
\hline $2-4$ & 1.41 & 6.68 & $14-16$ & 0.48 & 7.38 \\
\hline $4-6$ & 1.31 & 6.61 & $16-18$ & 0.52 & 7.06 \\
\hline $6-8$ & 1.04 & 7.67 & $18-20$ & 0.56 & 6.79 \\
\hline $8-10$ & 0.92 & 8.14 & $20-22$ & 0.51 & 7.60 \\
\hline $10-12$ & 0.64 & 9.09 & & & \\
\hline
\end{tabular}




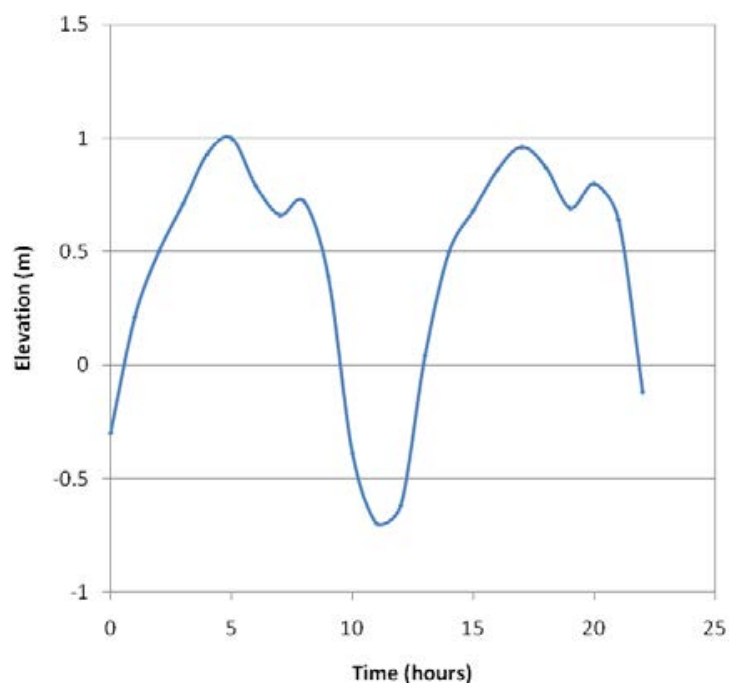

Figure 6: Tidal data

Figure 7 compares the initially observed beach profile with the profile observed after two tides and the model simulation. This blind first application of the model demonstrates that it is able to predict relatively well the major features of the profile change over one day. The location of the berm above the flood tide level agrees well with the measured berm development, although the magnitude of accretion here is less. Between the high water and low water levels (marked "ebb" and "flood"), the model predicts more erosion than measured in the field and the model deposits more sediment offshore, below the low water level. This may be due to the effect of bore collapse and breaking which is not considered in the current work. It is believed that as the beach become steeper, the effect of plunging waves and associated turbulence over the beach face increases. Hence this will affect the beach profile as discussed in Ting and Kirby (1994) and Pedrozo-Acuña et al. (2008). This bore collapse from plunging breakers play an important role in stirring up of sediment from the bed. This physical mechanism was observed in Pedrozo-Acuña et al. (2006, 2007 and 2008) during the experiments for gravel and mixed beaches at the GWK. It is also true that the model cannot yet simulate the effect of multiple grain fractions (the lower terrace is sand).

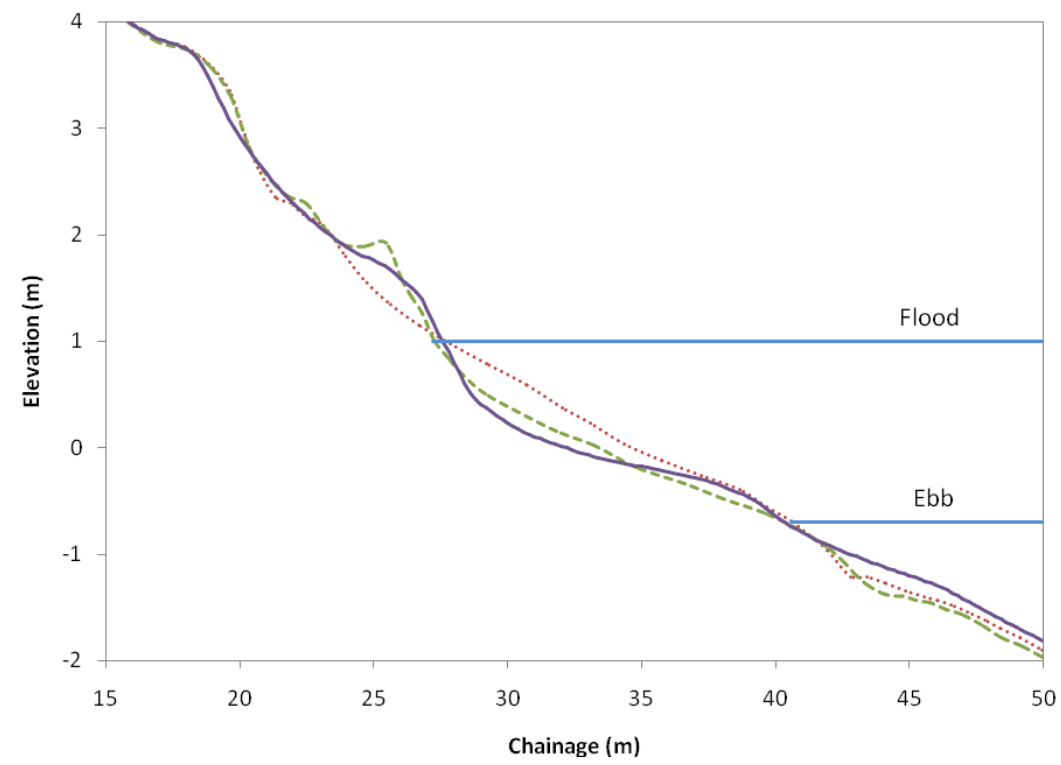

Figure 7 - Milford on Sea beach profile simulation: initial beach profile (dotted red); simulated profile (solid purple); measured profile (dashed green) 


\section{CONCLUSION}

The robustness of the X-Beach code allows longer (days) simulations to be performed and thus it is possible to simulate the effect of tidal excursion. Tides are known to affect the water table levels within the beach and this can affect infiltration and the subtle switch between beach steepening (accretion) and flattening (erosion). Here, the variant model was evaluated for its ability to simulate coarse beach profile dynamics in tidal environments. A tidal simulation, covering 24 hours on a semidiurnal tide with range of $2.5 \mathrm{~m}$ (low tide $=3.2 \mathrm{~m}$ and high tide $=5.7 \mathrm{~m}$ ) was compared with a similar length simulation with a stationary mean water level. The initial beach profile and wave conditions used were taken from those of a an experiment in the GWK. All the other model parameters such as permeability rate, friction factor and porosity were kept constant between the simulations. The model predictions show behaviour consistent with observations from laboratory experiments (Trim et al, 2002) and field experiments (Powell, 1990; Horn and Mason, 1994) in terms of the affected area, the rate of sediment transport (during flood and ebb) and the berm location and larger size under tidal conditions. An initial favourable comparison was also made between the model simulation and field observations from a composite beach at Milford on Sea, using the measured parameters.

In conclusion, it can be seen that this variant of the X-Beach model promises to lead to improved predictions of profile change on gravel beaches. Work is ongoing to validate the model for a wider selection of cases and to address some of the issues raised above.

\section{ACKNOWLEDGMENTS}

The large scale tests in the Large Wave Channel (GWK) of the Coastal Research Centre (FZK) were supported by the European Community under the Access to Research Infrastructures action of the Human Potential Programme (contract HPRI-CT-1999-00101).The authors would like to acknowledge the above project for the data provided to be used in this paper.

Mohamad H. Jamal is grateful to the Malaysian Government and Universiti Teknologi Malaysia for sponsorship of his research studies at the University of Plymouth, United Kingdom.

\section{REFERENCES}

Austin, M.J., Masselink, G., 2006. Swash-groundwater interaction on a steep gravel beach. Continental Shelf Research 26 (20), 2503-2519

Baldock, T.E., Holmes, P., 1997. Swash hydrodynamics on a steep beach. Proceedings Coastal Dynamics '97, ASCE, Plymouth, UK, pp. 784-793

Bradbury, A.P., 2000. Predicting breaching of shingle barrier beaches- recent advances to aid beach management. 35 ${ }^{\text {th }}$ MAFF (DEFRA) Conf. of River and Coastal Engineers.

Conley, D.C., Inman, D., 1994. Ventilated oscillatory boundary layers. Journal of Fluid Mechanics, 273, 261-284

Foote, M., Horn, D., Li, L., 2002. Measuring swash zone hydrodynamics and morphodynamic change a high-resolution laboratory system using digital video, Journal of Coastal Research SI, 36, 300 316

Horn, D.P., 2002. Beach groundwater dynamics. Geomorphology 48 (1-3), 121-146

Horn, D., Li, L., 2006. Measurement and modelling of gravel beach groundwater response to wave runup: effects on beach profile changes. Journal of Coastal Research, 22 (5), 1241-1249

Horn, D.P., Mason, T., 1994. Swash zone sediment transport mode. Marine Geology, 120 (3-4), 309325

Hughes, M., Masselink, G., Hanslow, D., Mitchell, D., 1997. Toward a better understanding of swash zone sediment transport. Proceedings of Coastal Dynamics '97. ASCE, Plymouth, UK, pp. 804813

Jamal, M.H., 2011. Modelling coarse-grained beach profile evolution. PhD Thesis, University of Plymouth, UK

Jamal, M.H., Simmonds, D.J., Magar, V., Pan, S., 2010. Modelling infiltration on gravel beaches with an XBeach variant. Proceedings of $32^{\text {nd }}$ International Conference on Coastal Engineering, No. 32(2010), Shanghai, China, paper no. 156, 1-11

Lee, K.H., Mizutani, N., Hur, D.S., Kamiya, A., 2007. The effect of groundwater on topographic changes in a gravel beach. Ocean Engineering 34 (3-4), 605-615

López de San Román-Blanco, B., 2003. Dynamics of gravel and mixed, sand and gravel beaches. PhD thesis, Imperial College, University of London, London, UK. 
Lynett, P.J., Wu, T.R., Liu, P.L.F., 2002. Modelling wave runup with depth-integrated equations. Coastal Engineering, 46 (2), 89-107

Mason, T., Coates, T.T., 2001. Sediment transport processes on mixed beaches: a review for shoreline management. Journal of Coastal Research 17 (3), 645-657

Mason, T., Priestley, D., Reeve, D.E., 2007. Monitoring near-shore shingle transport under waves using a passive acoustic technique. Journal of the Acoustical Society of America, 122 (2), 737-746

Masselink, G., Hegge, B., 1995. Morphodynamics of meso- and macrotidal beaches: examples from central Queensland, Australia. Marine Geology 129 (1-2), l-23

Masselink, G., Li, L., 2001. The role of swash infiltration in determining the beach face gradient: a numerical study. Marine Geology, 176 (1-4), 139-156

Masselink, G., Short, A.D., 1993. The effect of tide ranges on beach morphodynamics and morphology: A conceptual beach model. Journal of Coastal Research, 9 (3), 785-800

Meyer-Peter, E., Müller, R., 1948. Formulas for bed load transport, $2^{\text {nd }}$ Congress of the Int. Association of Hydraulics Structures Res., Stockholm, Sweden

Nielsen, P., Robert, S., Møller-Christiansen, B., Oliva, P., 2001. Infiltration effects on sediment mobility under waves. Coastal Engineering, 42 (2), 105-114

Packwood, A.R., 1983. The influence of beach porosity on wave uprush and backwash. Coastal Engineering, 7 (1), 29-40

Pedrozo-Acuña, A., 2005. Concerning swash on steep beaches. PhD thesis, University of Plymouth, U.K

Pedrozo-Acuña, A., Simmonds, D.J., Otta, A.K., Chadwick, A.J., 2006. On the cross-shore profile change of gravel beaches. Coastal Engineering, 53 (4), 335- 347

Pedrozo-Acuña, A., Simmonds, D.J., Chadwick, A.J., Silva, R., 2007. A numerical-empirical approach for evaluating morphodynamic processes on gravel and mixed sand-gravel beaches. Marine Geology, 241 (1-4), 1-18

Pedrozo-Acuña, A., Simmonds, D.J., Reeve, D.E., 2008. Wave-impact characteristics of plunging breakers acting on gravel beaches. Marine Geology, 253 (1-2), 26-35

Powell, K.A., 1990. Predicting Short Term Profile response for shingle beaches. Report SR 219, HR Wallingford, Oxfordshire, UK

Puleo, J.A., Beach, R.A., Holman, R.A., Allen, J.S., 2000. Swash zone sediment suspension and transport and the importance of bore-generated turbulence. Journal of Geophysical Research, 105 (C7), 17021-17044

Puleo, J.A., Holland, K.T., 2001. Estimating swash zone friction coefficients on sandy beach. Coastal Engineering, 43 (1), 25-40

Quick, M.C., 1991. Onshore-offshore sediment transport on beaches. Coastal Engineering 15 (4), 313332

Raubenheimer, B., Guza, R.T., Elgar, S., 1999. Tidal water table fluctuations in a sandy ocean beach. Water Resources Research 35 (8), 2313-2320

Roelvink, J.A, Reniers, A., van Dongeren, A., van Thiel de Vries, J., McCall, R., Lescinski, J., 2009. Modelling storm impacts on beaches, dunes and barrier islands. Coastal Engineering, 56 (11-12), 1133-1152

Simmonds, Davidson, Reeve, Chadwick, Dong, Spivack, Kizhisseri, Karunarathna, Wu 1997, "A Risk Based Framework for Predicting Long-term Beach Evolution” Proceedings of the 30th International Conference on Coastal Engineering .

Soulsby, R.L., 1997. Dynamics of Marine Sands. Thomas Telford, HR Wallingford, London, UK

Soulsby, R.L., Damgaard, J.S., 2005. Bedload sediment transport in coastal waters. Coastal Engineering, 52 (8), 673-689

Ting, F.C.K., Kirby, J.T., 1994. Observation of undertow and turbulence in a laboratory surf zone. Coastal Engineering, 24(1-2), 51-80

Trim, L.K., She, K., Pope, D.J., 2002. Tidal effects on cross-shore sediment transport on a shingle beach. Journal of Coastal Research SI, 36, 708-715

Turner, I.L., Masselink, G., 1998. Swash infiltration-exfiltration and sediment transport. Journal of Geophysical Research 103 (C13), 30813-30824

Van Gent, M.R.A., 1994. The modelling of wave action on and in coastal structures. Coastal Engineering, 22 (3-4), 311-339

Van Thiel de Vries, J.S.M., 2009. Dune erosion during storm surges. PhD thesis, Deltares, Netherland 
Williams, J., Ruiz de Alegria-Arzaburu, A., McCall R.T., Van Dongeren A., 2012. Modelling gravel barrier profile response to combined waves and tides using XBeach: Laboratory and fields results. Coastal Engineering, 63, 62-80

Wurjanto, A., Kobayashi, N., 1993. Irregular wave reflection and runup on permeable slope. Journal of Waterway, Port, Coastal, and Ocean Engineering, 119 (5), 537-557 